\title{
Criminologie
}

\section{In Memoriam : Micheline Baril}

\section{Maurice Cusson}

Volume 26, numéro 2, 1993

La criminologie comparée. Hommage à Denis Szabo

URI : https://id.erudit.org/iderudit/011178ar

DOI : https://doi.org/10.7202/011178ar

Aller au sommaire du numéro

Éditeur(s)

Les Presses de l'Université de Montréal

ISSN

0316-0041 (imprimé)

1492-1367 (numérique)

Découvrir la revue

Citer ce document

Cusson, M. (1993). In Memoriam : Micheline Baril. Criminologie, 26(2), 3-5. https://doi.org/10.7202/011178ar d'utilisation que vous pouvez consulter en ligne.

https://apropos.erudit.org/fr/usagers/politique-dutilisation/ 


\section{IN MEMORIAM}

\section{MICHELINE BARIL}

\section{Le 22 août 1993}

Avec le décès de Micheline Baril nous perdons une collegue et amie qui eût un rôle décisif à jouer dans l'amélioration du sort des victimes. Nous perdons aussi une belle intelligence ; un esprit fin, nuancé, juste et précis. C'est cette intelligence que je voudrais pour ma part évoquer.

Les écrits de Micheline ne jouissaient pas d'une large diffusion, mais ils furent influents, ils furent étonnamment influents. Je tenterai de dire pourquoi ils exercèrent une telle influence en évoquant brièvement quelques-unes des idées sur les victimes qui lui tenaient à cour.

C'est en 1977 que Micheline Baril fit paraître son premier rapport de recherche en victimilogie. Il s'intitulait «Les petits commerçants victimes de vol à main armée; en quête de justice ». Elle avait dirigé cette recherche de très près et elle en avait rédigé de larges parties mais - chose qui en dit long sur son excessive modestie - elle ne l'avait pas signée. À l'époque, la criminologie était encore affligée d'une grave erreur de perspective qui la conduisait à réduire son objet d'étude au criminel - un criminel qu'il fallait réhabiliter ou neutraliser, en tous les cas, traiter avec compassion. À cette époque, le crime était surtout conçu comme un symptôme; le fait qu'il causait généralement un préjudice à autrui n'était pas pris en compte dans nos théories. C'est Micheline Baril qui nous a ouvert les yeux. Nous étions bien sûr conscients de l'existence de la victime, mais nous pensions qu'elle n'avait d'intérêt que par sa contribution au crime. Micheline a vu toutes les implications du constat fondamental que les vols et les agressions sont des crimes, en premier lieu parce qu'ils lèsent une personne. Elle a compris que le point de vue de la victime est essentiel pour comprendre le crime. Elle appelait cela $l$ 'envers $d u$ crime, du titre de sa thèse de doctorat. «La vérité du crime, écrivait-elle, en 1981 , ce n'est pas uniquement la victime, mais c'est aussi la victime».

La plupart des criminologies sont simultanément des utilitaristes et des humanitaristes. Ils souhaitent que la protection de la société ne se fasse pas au détriment des délinquants. Micheline était animée de sentiments humanitaires, mais elle n'était pas utilitariste. Elle était d'abord «En quête de justice». Les questions qui la préoccupaient étaient «Qu'est-ce que la justice ?» et «Justice pourquoi ?».

C'est son sens de la justice qui la conduisait à s'indigner devant le sort fait aux victimes d'actes criminels. Elle constate alors que le policier reste trop souvent passif devant la violence conjugale. L'avocat de la défense discrédite et ridiculise la victime qui est contrainte à témoigner. Le juge lui 
impose le silence. La victime ne peut pas récupérer les biens qui lui ont été volés. Elle ne touche ni compensation, ni indemnisation. Elle n'est pas protégée contre son agresseur qui continue de la menacer. Elle n'a pas la satisfaction de «justice rendue» (Baril 1985).

Pour comprendre ces aberrations, Micheline a interrogé l'histoire. Elle a compris, et elle nous a fait comprendre, que la situation actuelle des victimes est le résultat d'une évolution séculaire au cours de laquelle les personnes lésées par le délit ont progressivement été dépouillées de leurs droits. Au cours des siècles, la victime d'un crime cesse d'être pensée comme un sujet de droit pour être réduite au rôle de témoin - de «pion de la Reine». Cependant, cette évolution n'est pas inéluctable. Il nous faut restaurer la victime dans ses droits. Mais au nom de quel principe et avec quels risques?

Contrairement à ce que l'on en dit, notre amie voyait bien que la restauration de la victime dans ses droits ne peut pas ne pas limiter les privilèges dont jouissent actuellement les accusés et les délinquants condamnés. «Les personnes lésées par les actes criminels, écrivait-elle en 1985 , ont perdu leurs droits ou privilèges au même rythme que les délinquants en ont acquis» (p.106). C'est en vertu du droit de l'accuse à une défense pleine et entière que les victimes sont harcelées, ridiculisées et quelquefois terrorisées (p. 109). «Dans un louable souci de ne pas condamner un innocent, souci qui s'est transformé en obsession, on a accablé la victime d'obligations sans lui accorder en contrepartie le moindre droit ou privilège» (p. 108). Elle prévoyait que la «reconnaissance des droits des victimes limitera l'exercice des droits et privileges des accusés et condamnés » (p. 106). Mais cette reconnaissance lui paraissait devoir s'imposer : la justice la plus élémentaire l'exige. 11 faut obliger le criminel à la réparation intégrale du préjudice même si cela rend le crime moins payant. Il faut faire participer la victime au processus pénal en lui permettant d'être représentée par un avocat, de donner sa version des faits, de donner son avis lors de la négociation du plaidoyer. Dans un texte de 1985, elle raisonnait en termes d'économie des droits : ies droits des agresseurs trouvent leur limite dans les droits de l'agressé. Et elle proposait une distribution plus équitable des droits entre les criminels et leurs victimes en s'inspirant de la règle de proportionnalité.

C'est une belle intelligence que nous perdons avec le décès de Micheline. Elle savait marier mieux que quiconque la recherche empirique et la réflexion théorique. Sa pensée était efficace. À ce titre elle représente un idéal pour les criminologues.

Elle était un chercheur exceptionnellement doué. Ses projets de recherche étaient de véritables bijoux et presque toujours, elle obtenait les subventions demandées. Elle s'est surtout distinguée dans la recherche 
qualitative sans pour autant s'y limiter. Combinant l'écoute attentive et sympathique, la lucidité et la perspicacité, ses analyses étaient toutes de nuances. Elle ne cherchait pas à défendre une thèse mais plutôt à rendre compte de la diversité des phénomènes, de ses contrastes et de ses paradoxes.

Sous des dehors inoffensifs elle avait un sens critique aigu. Ses critiques pouvaient être radicales, mais elles n'étaient jamais dogmatiques. C'était les critiques de celle qui connaît les rouages du système et qui a compris comment on pouvait en être victime. C'étaient des critiques qui donnaient l'espoir car elles débouchaient sur des solutions réalisables.

Micheline Baril savait convaincre et ses analyses ont contribué au changement. C'est grâce à elle que, par exemple, la déclaration de la victime fut acceptée au Palais de justice et que l'on y créa un service à la clientèle.

Pourquoi cette femme discrète, effacée, excessivement modeste, et pratiquement sans pouvoir eut-elle cette influence? Plus que par sa ténacité bien connue, il me semble que cela s'explique par ses qualités intellectuelles. Notre collègue et amie pensait juste; elle allait à l'essentiel; elle voyait les vrais problèmes; elle fondait ses démonstrations sur des faits bien établis; elle écrivait de manière simple, limpide et convaincante. Sa pensée était précise et forte mais d'une force retenue.

Micheline Baril était au service de la vérité et de la justice. C'est en s'appuyant sur la vérité et en faisant appel au sens de la justice de ses interlocuteurs qu'elle sut convaincre. Nous lui sommes reconnaissants pour tout ce qu'elle nous a apporté durant sa vie qui fut trop courte, beaucoup trop courte.

Maurice Cusson 